\title{
Metronidazole Release Using Natural Rubber Latex as Matrix
}

\author{
Rondinelli Donizetti Herculano ${ }^{a}$, Sérgio Augusto Catanzaro Guimarães ${ }^{b}$, \\ Gustavo Campos Belmonte, Marco Antonio Hungaro Duarte ${ }^{b}$, Osvaldo Novais de Oliveira Júnior ${ }^{a}$, \\ Angela Kinoshita ${ }^{b}$, Carlos Frederico de Oliveira Graeff ${ }^{2}$ \\ ${ }^{a}$ Departamento de Física e Ciências dos Materiais, Instituto de Física de São Carlos - IFSC, USP, \\ Av. Trabalhador Sancarlense, 400, 13560-970 São Carlos - SP, Brazil \\ ${ }^{b}$ Universidade do Sagrado Coração, \\ Rua Irmã Arminda, 10-50, 17011-160 Bauru - SP, Brazil \\ ${ }^{c}$ Departamento de Física, Faculdade de Ciências - FC, UNESP, \\ Av. Luis Edmundo Carrijo Coube, 14-01, 17033-360 Bauru - SP, Brazil
}

Received: August 28, 2009 Revised: February 1, 2010

\begin{abstract}
Natural Rubber Latex (NRL) can be used successfully in controlled release drug delivery due to their excellent matrix forming properties. Recently, NRL has shown to stimulate angiogenesis, cellular adhesion and the formation of extracellular matrix, promoting the replacement and regeneration of tissue. A dermatological delivery system comprising a topically acceptable, inert support impregnated with a metronidazole (MET) solution was developed. MET 2-(2- methyl- 5-nitro- 1H- imidazol- 1-yl) ethanol, has been widely used for the treatment of protozoa and anaerobic bacterial infections. MET is a nitroimidazole anti-infective medication used mainly in the treatment of infections caused by susceptible organisms, particularly anaerobic bacteria and protozoa. In a previous study, we have tested NRL as an occlusive membrane for GBR with promising results. One possible way to decrease the inflammatory process, it was incorporated the MET in NRL. MET was incorporated into the NRL, by mixing it in solution for in vitro protein delivery experiments. The solutions of latex and MET were polymerized at different temperatures, from -100 to $40{ }^{\circ} \mathrm{C}$, in order to control the membrane morphology. SEM microscopy analysis showed that the number, size and distribution of pores in NRL membranes varied depending on polymerization temperature, as well as its overall morphology. Results demonstrated that the best drug-delivery system was the membrane polymerized at $-100{ }^{\circ} \mathrm{C}$, which does release $77,1 \%$ of its MET content for up 310 hours.
\end{abstract}

Keywords: biomaterials, latex membrane, metronidazole, drug delivery system

\section{Introduction}

Metronidazole 2-(2- methyl- 5-nitro- 1H- imidazol- 1-yl) ethanol is a cytostatic drug effective for treatment of rosacea, a common chronic syndrome characterized by persistent facial erythema, flushing, edema, pustules, and papules ${ }^{1-2}$. It is available in gel formulation for the treatment of bacterial vaginosis as well as in topical gel and cream for the treatment of inflammatory lesions and erythema of rosacea $^{3-5}$. Metronidazole (MET) is very effective for treatment of rosacea not only after systemic administration but also after topical application. To our knowledge, none of these methods have been validated for the release of MET in dermatological formulations.

We reported here a novel sustained delivery system for MET based on Natural Rubber Latex (NRL). NRL membrane from Hevea brasiliensis has interesting characteristics related to this work such as: it is easy to manipulate, low cost, can stimulate the natural angiogenesis, is a biocompatible material and presents high mechanical resistance. In according to literature, it is well known that NRL can give allergic reactions and has cytoxicity problems, which is of great concern especially on these new applications where NRL is used inside the human body ${ }^{6-8}$. However recently, several new biomedical applications for NRL have been proposed using a different manufacturing process (NRLb) ${ }^{9-12}$. Thus NRLb is processed avoiding the use of chemicals such as carbamates and sulphur, as well as does not suffer any heat treatments. Apparently this way of producing NRLb produces a much better biocompatible material ${ }^{13-16}$. In fact, NRLb is now commercialized in Brazil and other 60 countries as a band-aid curative $\left(\mathrm{BIOCURE}^{\circledR}\right)$ for the treatment of ulcers in diabetic patients among other applications ${ }^{17}$.
In a previous study, $\mathrm{NRb}$ was tested as an occlusive membrane for Guided Bone Regeneration (GBR) ${ }^{18}$. The membrane was used in a critical defect in the rabbit calvaria, and did help healing the wound. In principle, NRL worked as a passive barrier membrane that prevented epithelial and connective tissue migration, thus facilitating the proliferation and migration of regenerative cells, such as osteoblasts, into the protected wound. One possible way to decrease the inflammatory process, it was incorporated the MET in NRL. MET was incorporated into the NRLb, by mixing it in solution for in vitro protein delivery experiments.

Thus the ideal membrane would have to release MET along many weeks. So in this work different polymerization conditions were used in order to control the MET release of NRLb. NRLb polymerized under different conditions, and with the incorporation of MET was characterized by Scanning Electron Microscopy (SEM), while membrane release of MET was characterized by the UV-VIS method. Results show that the NRLb membrane can release MET for up to 310 hours.

\section{Experimental Procedures}

Metronidazole 2-(2- methyl- 5-nitro- 1H- imidazol- 1-yl) ethanol was purchased from BIOFLORA Pharmaceutical Ltd., Brazil. The latex solution extracted from Hevea brasiliensis consisted in a mixture of different clones. The extraction was made in ESALQ-USP, Piracicaba, Brazil. After extraction, ammonia was used to keep the latex 


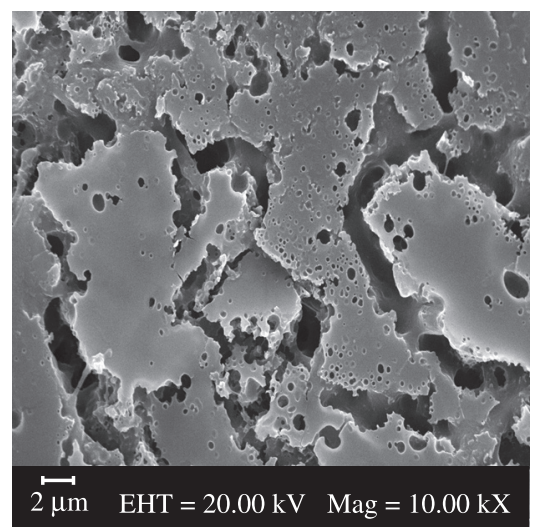

(a)

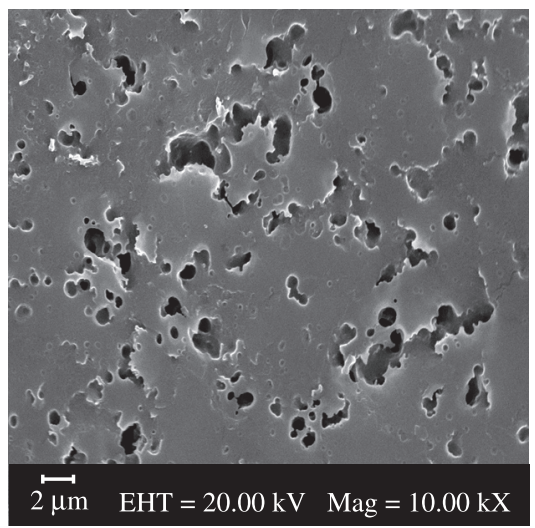

(b)

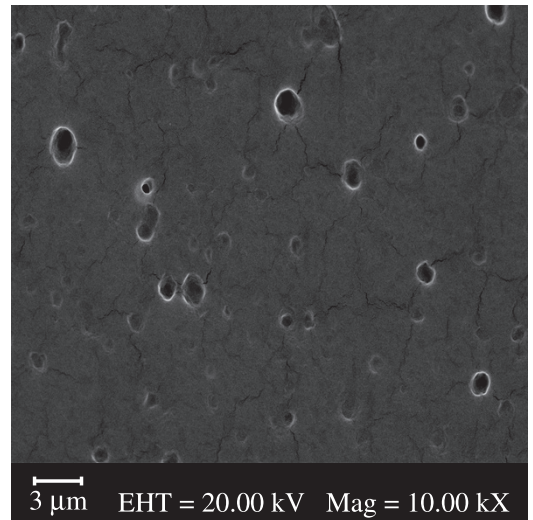

(c)

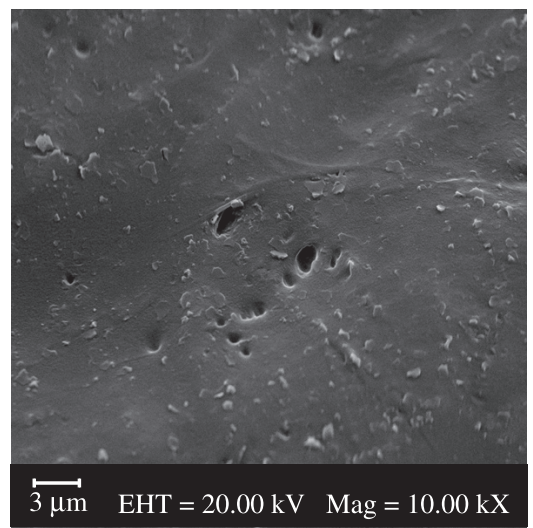

(d)

Figure 1. SEM images (magnification: $\times 10,000)$ of NRLb membranes with MET: a) Polymerized at $-100^{\circ} \mathrm{C}$, (b) Polymerized at $-10^{\circ} \mathrm{C}, \mathrm{c}$ ) Polymerized at RT and d) Polymerized at $40{ }^{\circ} \mathrm{C}$. Notice the difference in the pores density. liquid, and this material was centrifuged at $8000 \mathrm{~g}$. The centrifugation was employed to reduce the protein content of NRLb ${ }^{15}$.

In this work, membranes with $2 \mathrm{~mL}$ of natural rubber $+1 \mathrm{~mL}$ of metronidazole solution $\left(10 \mathrm{mg} . \mathrm{mL}^{-1}\right)$ were produced. These membranes were prepared by pouring the latex+MET (NRLbMET) solution in a stainless steel plate with $5.00 \pm 0.05 \mathrm{~cm}$ diameter, and left at different temperatures for polymerization: $-100,-10,27^{\circ} \mathrm{C}$ (Room Temperture) and $40{ }^{\circ} \mathrm{C}$ during 2 hours. The temperatures chosen are known to change the porosity of the membranes ${ }^{19-21}$. After this, the solution was left in air for 2 day to complete the polymerization process resulting in an elastic membrane. Finally, the NRLb membrane is sterilized using ethylene oxide.

For the drug release study NRLbMET membranes were placed in $200 \mathrm{~mL}$ of aqueous solution, where the release behavior was observed. Aliquots of this solution were collected during an interval ranging from 10 to 24,000 minutes. The MET release as a function of time was determined using the UV-VIS method. The morphology of membrane surface was observed using a Scanning Electron Microscocopy (SEM) model Zeiss ${ }^{\circledR}$ EVO 50 (15 KV) and X-ray diffraction and Energy Dispersive X-ray spectroscopy (EDS-SEM) with take off angle of $35^{\circ}$.

\section{Results}

According to Herculano et al. ${ }^{21}$, Thermally Induced Phase Separation (TIPS) is a method to make microporous membrane ${ }^{22-24}$. This procedure is perhaps the most versatile and simplest membrane preparation technique. In this work, NRLb membranes were prepared in four different polymerization temperatures: $-100,-10,27{ }^{\circ} \mathrm{C}$ (RT) and $40{ }^{\circ} \mathrm{C}$. Figure 1 shows typical SEM images of membranes polymerized at different temperatures. As can be seen, the pore sizes and density vary with polymerization temperature. NRLb polymerized at $-100{ }^{\circ} \mathrm{C}$ (Figure 1a), $-10{ }^{\circ} \mathrm{C}$ (Figure 1b) and RT (Figure 1c) have pores, while those membranes polymerized at RT $40{ }^{\circ} \mathrm{C}$ almost do not have. The density of pores is higher as the polymerization temperature diminishes. Pore sizes with diameters ranging from 0.49 to $5.12 \mu \mathrm{m}$ were observed on the NRLb+MET membrane polymerized at $-100{ }^{\circ} \mathrm{C}$ (Figure 1a), while the membrane polymerized at $-10^{\circ} \mathrm{C}$ displayed pore sizes of dimensions from 1.17 to $3.16 \mu \mathrm{m}$ (Figure 1b) and membrane polymerized at RT displayed pores size of similar dimensions $(1.03 \pm 0.28) \mu \mathrm{m}$ (Figure 1c).

In Figure 2 shows the absorbance intensity as a function of MET concentration in solution. This calibration curve is important

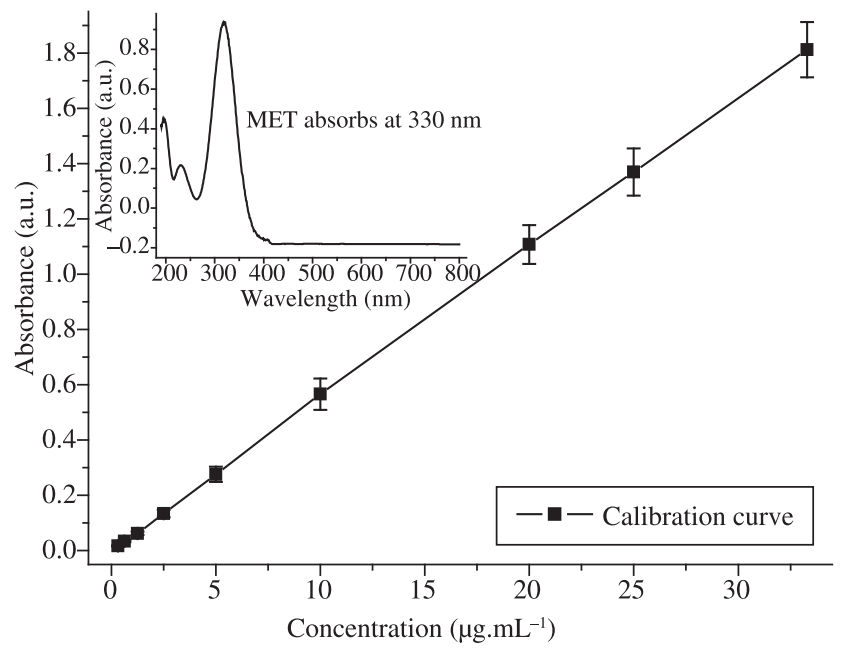

Figure 2. Absorbance intensity as a function of MET concentration in solution. The insert graph shows a typical spectrum of MET. 
because to make one relationship between absorbance and the MET concentration. For this experiment several MET concentrations from 0.3 to $33 \mu \mathrm{g} \cdot \mathrm{mL}^{-1}$ were made. After this, it was measurement your absorbance. Using a calibration curve, an unknown concentration can be derived from a sample by measuring it's response and then finding the corresponding y-axis intercept. Note that the insert graph shows a typical spectrum of MET. The MET solution absorbs at $330 \mathrm{~nm}$.

In Figure 3 MET release as a function of time is presented for membranes polymerized in similar conditions to the ones presented in Figure 1. The release from the membrane polymerized at $-100{ }^{\circ} \mathrm{C}$ is higher than other membranes. The membrane polymerized at $-1{ }^{\circ} \mathrm{C}$ not is presented because your pore density and consequently MET release rate is similar than membrane polymerized at $-10{ }^{\circ} \mathrm{C}$. The 4 membranes reach saturation at different concentrations. In other words, the total amount of MET released by the membrane depends on the latex polymerization temperature. The uncertainties of MET release as a function of time (Figure 3 ) measurements were of 2-5\%.

The experimental data in Figure 3 were fitted using a bi-exponential function $\mathrm{y}(\mathrm{t})=\mathrm{y}_{0}+\mathrm{A}_{1} \mathrm{e}^{-t /} \tau_{1}+\mathrm{A}_{2} \mathrm{e}^{-\mathrm{t} /} \tau_{2}$, where $\mathrm{y}(\mathrm{t})$ was the amount of MET in the NRL at a given time, $t, y_{0}$ is the initial content of MET, $A_{1}$ and $A_{2}$ are constants and the are $\tau_{1}$ and $\tau_{2}$ are characteristic times. The Table 1 show the constants $\mathrm{A}_{1}$ and $\mathrm{A}_{2}$, and the characteristic times $\tau_{1}$ and $\tau_{2}$ of the natural rubber membranes polymerized at different temperatures.

After integration of these curves until 310 hours, the total amount of MET released by the three membranes in $200 \mathrm{~mL}$ aqueous solution were: $15.41 \mathrm{mg}(77.1 \%$ of the MET used in the starting material) for membrane polymerized at $-100{ }^{\circ} \mathrm{C}$ and $11.86 \mathrm{mg}(59.00 \%)$ for $-10{ }^{\circ} \mathrm{C}, 10.63 \mathrm{mg}(53.15 \%)$ for RT and $9.40 \mathrm{mg}(47.02 \%)$ for $40{ }^{\circ} \mathrm{C}$ membranes respectively.

\section{Discussion}

In this work, it was used the method proposed by Langer \& Folkman $^{25}$, that is, to mix the protein (MET) with the polymer (latex)

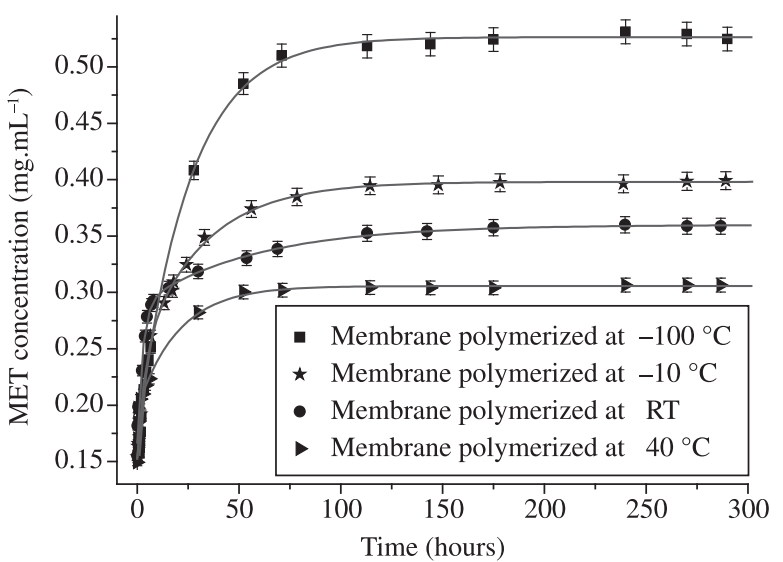

Figure 3. MET release as a function of time for NRL membrane prepared at different temperatures: $100{ }^{\circ} \mathrm{C},-10^{\circ} \mathrm{C}$, RT and $40{ }^{\circ} \mathrm{C}$. in a colloidal state, in order to create a membrane that works as a delivery system.

Several procedures are used to control the release of substances by polymers. For example Woo et al. ${ }^{26}$ used a combination of 3 different biodegradable microspheres of poly(D,L,-lactide-co-glycolide (PLGA)), using different molecular weight and terminal endings of the polymeric chain (hydrophilic or hydrophobic) to determine the best delivery system of BMP. They conclude that the best bone

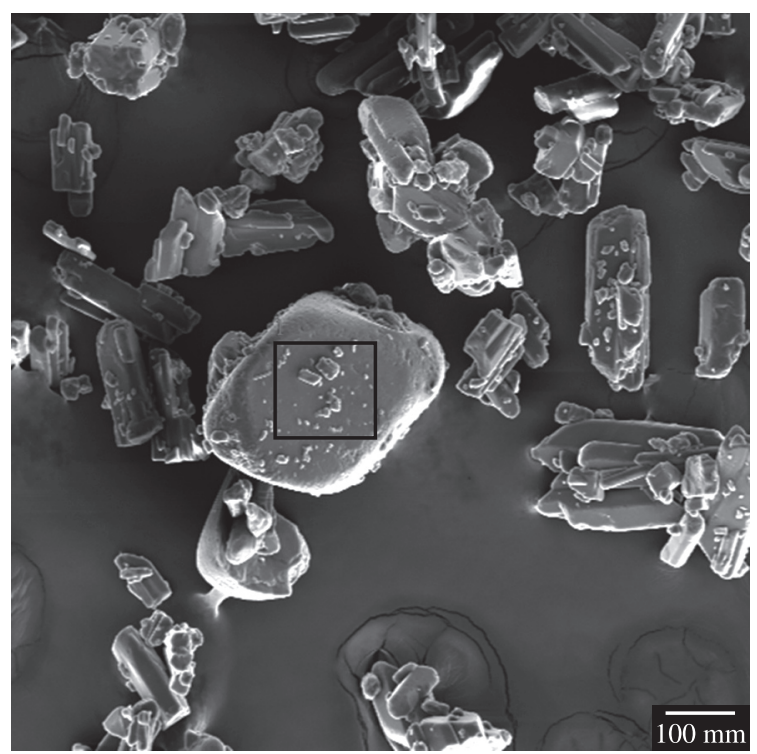

(a)

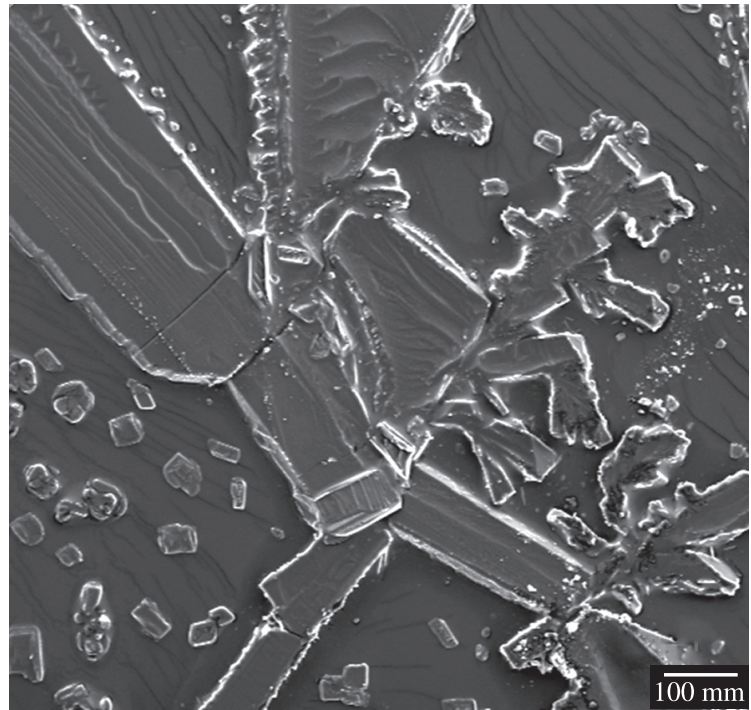

(b)

Figure 4. SEM-EDS spectra of: a) Metronidazole powder, c) and e) Natural Rubber membrane + Metronidazole. Notice that the MET is present on surface.

Table 1. $\mathrm{A}_{1}$ and $\mathrm{A}_{2}$ are constants and the $\tau_{1}$ and $\tau_{2}$ are characteristic times of the NRLb membranes prepared at different polymerization temperatures: -100 , $-10,27(\mathrm{RT})$ and $40^{\circ} \mathrm{C}$.

\begin{tabular}{cccrr}
\hline Natural rubber membranes & $\mathrm{A}_{1}$ & $\mathrm{~A}_{2}$ & $\tau_{1}$ & \multicolumn{1}{c}{$\tau_{2}$} \\
\hline Polymerized at $-100^{\circ} \mathrm{C}$ & -2.199 & -3.559 & 0.655 & 24.766 \\
Polymerized at $-10{ }^{\circ} \mathrm{C}$ & -1.610 & -0.816 & 29.941 & 3.581 \\
Polymerized at $\mathrm{RT}$ & -1.210 & -0.699 & 2.788 & 58.066 \\
Polymerized at $40{ }^{\circ} \mathrm{C}$ & -0.359 & -1.095 & 0.062 & 19.340 \\
\hline
\end{tabular}


healing results were achieved using high dose and slow delivery rate systems. They used animal models in their study.

In this work, as already mentioned different polymerization temperature was used in order to control the MET release rate. The SEM images (Figure 1) shows that polymerization temperature determines the morphology of the surface, producing pores and controlling the pores density. The pores density for membranes polymerized at -100 , $-10{ }^{\circ} \mathrm{C}$ are higher compared at RT and $40{ }^{\circ} \mathrm{C}$. Almost no pores were observed in membranes polymerized at $40{ }^{\circ} \mathrm{C}$.

The release profile for MET in a NRL matrix in Figure 3 shows that the first, fast step of burst release corresponded to the MET near or on the surface of the NRL membrane. The slower release process would be associated with MET diffusing slowly through the matrix. Thus, the drug is not found in the more inner portion of the polymeric matrix, as can be inferred from Figure 4. Thus the MET release depends mainly on the amount of encapsulated material on surface (as a reservoir) and not on diffusion.

The release rate was also affected by temperature (Figure 3). It was observed that the NRL membrane polymerized at $-100{ }^{\circ} \mathrm{C}$ presented the highest MET release. These results are in good agreement with those by Wang et al. ${ }^{27}$. They used different amounts of glutaraldehyde in chitosan synthesis in micro sphere form to obtain different cross-linking degrees, and monitored its effect on BSA release. They found that as cross-linking increases the release rate becames slower.

Notice that the molecule release after 310 hours, was $77.1 \%$ of the MET initially incorporated in the membrane polymerized at the $-100{ }^{\circ} \mathrm{C}, 59.00 \%$ for the membrane polymerized at $-10{ }^{\circ} \mathrm{C}, 53.15 \%$ for the membrane polymerized at RT and $47.02 \%$ for the membrane polymerized at $40^{\circ} \mathrm{C}$.

As mentioned earlier the controlled release of proteins is of interest for medical applications, since the dose can be adjusted according to the application envisaged. Our results indicate that with very simple changes in NRL preparation it is possible to control MET release up to 15 days, thus making them promising materials for protein release in in vivo applications.

All sample of NRL aggregate with MET, has the best potential for MET release, according to the Woo et al. ${ }^{26}$ results. It was shown that these membranes delivered the incorporated MET in 310 hours, or in other words with a slow release rate.

\section{Conclusion}

The sustained delivery system for MET has been successfully developed based on NRLb. The rate release of MET was controlled varying the polymerization temperature of the latex matrix. It was shown that polymerization temperature determines the morphology of the surface, producing pores and controlling the pores density. Results indicate that with very simple changes in NRLb preparation it is possible to control MET release up to 310 hours, thus making them promising materials for protein release in in vivo applications. Particularly the NRLb polymerized at $-100{ }^{\circ} \mathrm{C}$ has the best potential for MET release. For this membrane $77.1 \%$ of the initial MET content inside NRL was released in 310 hours, or in other words with a slow release rate. The SEM-EDS and the release behavior indicated that MET remains close or on the surface of the membrane. The drug is not found in the inner portion of the membrane.

\section{Acknowledgements}

We are grateful to J. L. Aziani, C. A. Brunello for technical support and $\mathrm{C}$ for the use of the Beckman DU-640 Spectrophotometer. This work received financial support from FAPESP, CNPq/IMMP and CAPES.

\section{References}

1. Martindale WH. The Extra Pharmacopoeia. 27 ed. London: The Pharmaceutical Press; 1977. p. 1570.

2. Cosar C, Julon L and Ganter P. Experimental study on metronidazole ( 8823 RP) - trichomonacid and amaebicid activites - toxicity and chomonacid and amaebicid activities - toxicity and general pharmacologic properties. Presse Medicale. 1961; 69(24):1069-1072.

3. Cosar C and Julon L. Activity of (Hydroxy-2' Ethyl)-1 Methyl-2 Nitro-5 Imidazole (8823 RP) in experimental trichomonas-vaginalis infections. Annales del'Institut Pasteur. 1959; 96(2):238-241.

4. Erk N and Altun ML. Spectrophotometric resolution of metronidazole and miconazole nitrate in ovules using ratio spectra derivative spectrophotometry and RP-LC. Journal of Pharmaceutical and Biomedical Analysis. 2001; 25(1):115-122.

5. Dinesh ND, Nagaraja P and Rangappa KS. A sensitive spectrophotometric assay for tinidazole and metronidazole using a Pd-C and formic acid reduction system. Turkish Journal of Chemistry. 2004; 28(3):335-343.

6. Nutter AF. Contact urticaria to rubber. British Journal of Dermatology. 1979; 101(5):597-598.

7. de Silva HD, Gardner LM, Drew AC, Beezhold DH, Rolland JM and O'Hehir RE. The hevein domain of the major latex-glove allergen Hev b 6.01 contains dominant $\mathrm{T}$ cell reactive sites. Clinical \& Experimental Allergy. 2004; 34(4):611-618.

8. Smith AM, Amin HS, Biagini RE, Hamilton RG, Arif SA, Yeang HY et al. Percutaneous reactivity to natural rubber latex proteins persists in health-care workers following avoidance of natural rubber latex. Clinical \& Experimental Allergy. 2007; 37(9):1349-1356.

9. Neves-Junior WFP, Graeff CFO, Ferreira M, Mulato M, Bernardes MS and Coutinho-Netto J. Elastic properties of natural rubber tubes produced by dip-coating. Journal of Applied Polymer Science. 2006; 100(1):702-707.

10. Herculano RD, Brunello CA and Graeff CFO. Solid state Nitric Oxide sensor using a latex rubber matrix. Macromolecular Symposia. 2006; 245-246(1):529-532.

11. Neves-Junior WFP, Ferreira M, Alves MCO, Graeff CFO, Bernardes MS, Coutinho-Netto J et al. Influence of fabrication process on the final properties of natural-rubber latex tubes for vascular prosthesis. Brazilian Journal of Phyics. 2006; 36(2B):586-591.

12. Herculano RD, Brunello CA and Graeff CFO. Optimization of a novel Nitric Oxide Sensor using a latex rubber matrix. Journal of Applied Science. 2007; 7(23):3801-3805.

13. Balabanian CACA, Coutinho Netto J, Lamano-Carvalho TL, Lacerda AS and Brentegani LG. Biocompatibility of natural latex implanted into dental alveolus of rats. Journal of Oral Science. 2006; 48(4):201-205.

14. Frade MAC, Valverde RV, Assis RVC, Coutinho-Netto J and Foss NT. Chronic phlebopathic cutaneous ulcer: a therapeutic proposal. International Journal of Dermatology. 2001; 40(3):237-240.

15. Mrué F, Coutinho-Netto J, Ceneviva R, Lachat JJ, Thomazini JA and Tambelini H. Evaluation of the biocompatibility of a new biomembrane. Materials Research. 2004; 7(2):277-283.

16. Ciapetti G, Stea S, Pizzoferrato A, Checchi L and Pelliccioni GA. A latex membrane, as an alternative device in the GTR technique: preliminary report on its biocompatibility. Journal of Materials Science: Materials in Medicine. 1994; 5(9-10):647-650.

17. Pele Nova. Biocure. [on-line]. Available from: http://www.pelenova.com. br/site. Access in: July 2009.

18. Ereno C, Catanzaro-Guimarães SA, Pasetto S, Holgado L, Herculano $\mathrm{RD}$, Silva $\mathrm{CP}$ et al. Latex use as an occlusive membrane for guided bone regeneration. Journal of Biomedical Materials Research. Part A, (paper submitted).

19. Lloyd DR, Kinzer KE and Tseng HS. Microporous membrane formation via thermally induced phase separation. I. Solid-liquid phase separation. Journal of Membrane. Science. 1990; 52(3):239-261. 
20. Lloyd DR, Kim SS and Kinzer KE. Microporous membrane formation via thermally-induced phase separation. II. Liquid-liquid phase separation. Journal of Membrane Science. 1991; 64(1-2):1-11.

21. Herculano RD, Pereira CP, Ereno C, Catanzaro-Guimarães SAC, Kinoshita A and Graeff CFO. Natural rubber latex used as drug delivery system in guided bone regeneration (GBR). Materials Research. 2009; 12(2):253-256

22. Matsuyama H, Yuasa M, Kitamura Y, Teramoto M and Lloyd DR. Structure control of anisotropic and asymmetric polypropylene membrane prepared by thermally induced phase separation. Journal of Membrane Science. 2000; 179(1-2):91-100.

23. Yave W, Quijada R, Ulbricht M and Benavente R. Syndiotactic polypropylene as potential material for the preparation of porous membranes via thermally induced phase separation (TIPS) process. Polymer. 2005; 46(25):11582-11590.
24. Graham PD, Pervan AJ and McHugh AJ.The dynamics of thermal-induced phase separation in PMMA Solutions. Macromolecules. 1997, 30(6):1651-1655.

25. Folkman $\mathrm{J}$ and Langer R. Polymers for the sustained release of proteins and other macromolecules. Nature. 1976; 263(5580):797-800.

26. Woo BH, Fink BF, Page R, Schrier JA, Woo Jo Y, Jiang G et al. Enhancement of bone growth by sustained delivery of recombinant human bone morphogenetic protein-2 in a polymeric matrix. Pharmaceutical Research. 2001; 18(12):1747-1753.

27. Wang LY, Ma GH and Su ZG. Preparation of uniform sized chitosan microspheres by membrane emulsification technique and application as a carrier of protein drug. Journal of Controlled Release. 2005; 106(1-2):62-75. 
